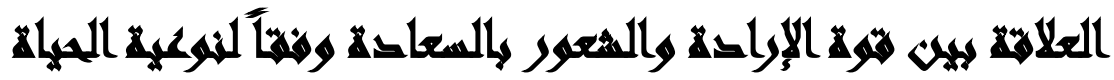

[iv]

\author{
أحمد مصطفى العتيق(')- أحمد فخري هاني(')- هالة عادل يس

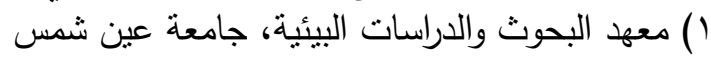 \\ المستحلص
}

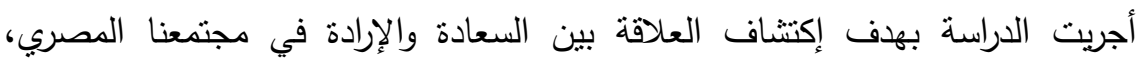

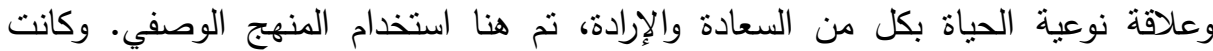

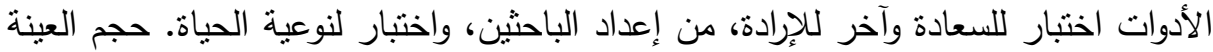

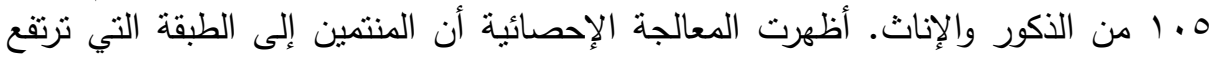

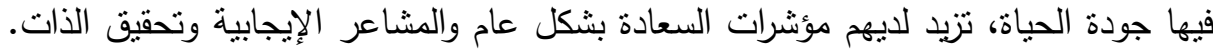

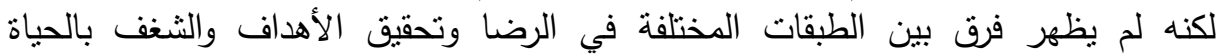

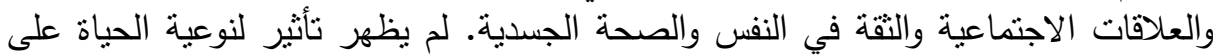

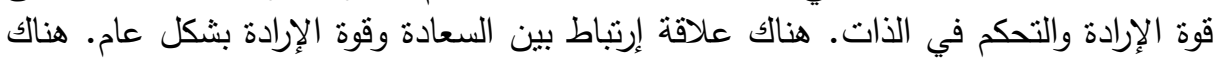

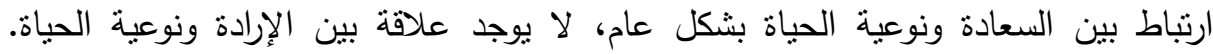

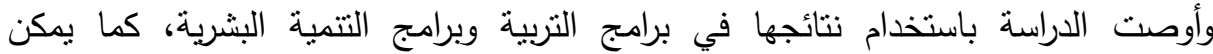

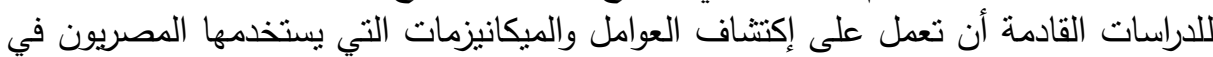
مواجهة صعوبات الحياة والتوصل إلى تلى تحقيق أهدافهر.

\section{Lantl}

إن الدراسة الحالية تهدف إلى إكتثاف العلاقة بين السعادة والإرادة في ضوء نوعية

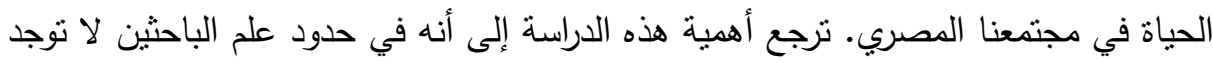
دراسة في الوطن العربي تتتاول موضوع السعادة والإرادة حتى الآن. والدراسات النفسية العربية

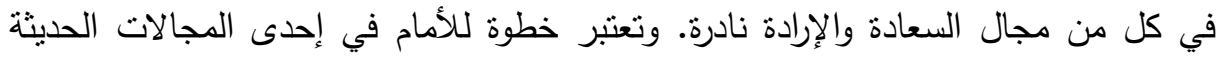
وهي علم النفس الإيجابي، وتساهم في نشره في مصر . كما توفر مقاييس جديدة للسعادة

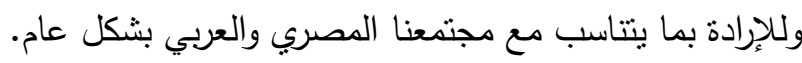

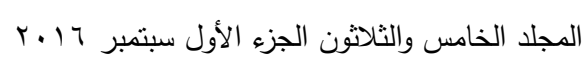


إن الحصول على السعادة هو هدف البشر في كل زمان ومكان. (Richardson،

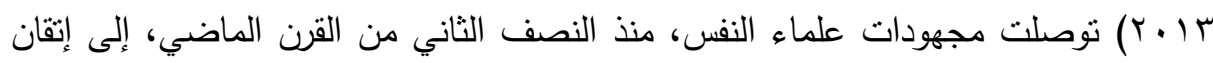
تتخيص الأمراض النفسية وعلاجها، لكن هذا لا يفيد كثيرا من يريد أن يزيد من سعادته ويرفع

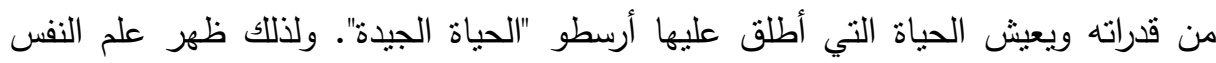
الإيجابي والذي يعنى بدراسة المشاعر والسمات الثخصية والروابط الإجتماعية الإيجابية.

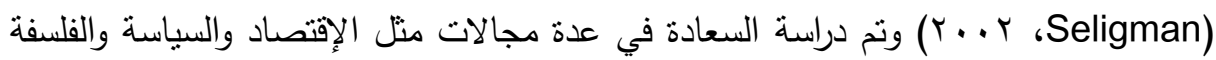
وعلم النفس. وأكدت الدراسات على أن إرتفاع المستوى الاقتصادي لايرتبط بشعور الفرد

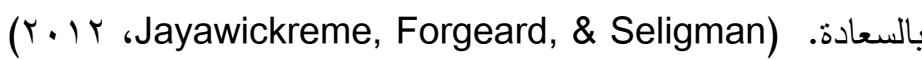
إن دراسة السعادة يجب أن تتم على أساس دراسة أهم r جذور للسعادة وهي: المشاعر

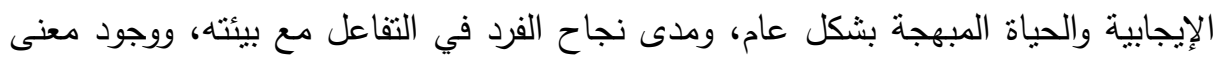

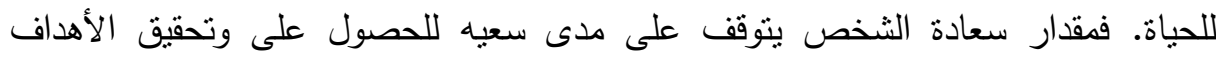

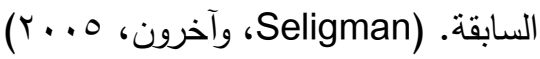
وتحقيق الأهداف برتبط بالإرادة، والتي ينم تتميتها في سن الطفولة. وتبدأ في البداية

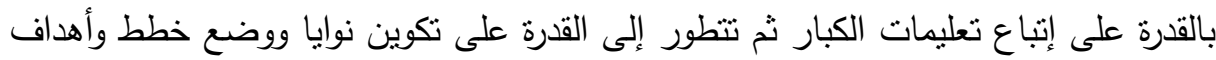

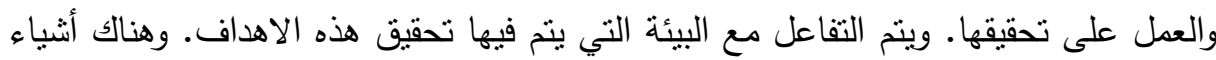
على الثخص تقبلها كما هي لأنه لايستطيع تغييرها، وأثياءاً أخرى يمكنه تغييرها ببذل الجئل الجهد. ( $r$..人 ،Miller, \& Atencio)

\section{xall 12 and}

قامت بعض الدراسات القليلة في الدول الغربية بتتاول التأثثر المتبادل بين الإرادة

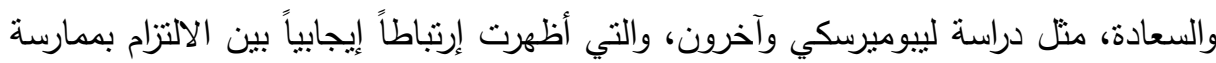

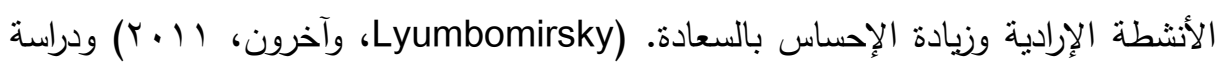
إياني التي أوضحت أن الوصول إلى الأهداف يساهم في شعور الفرد بالسعادة (lanni)،

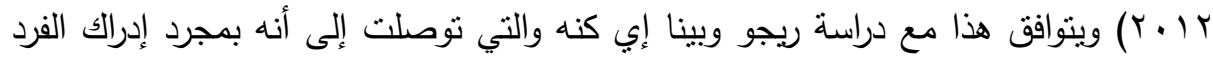

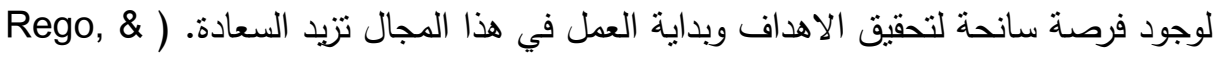




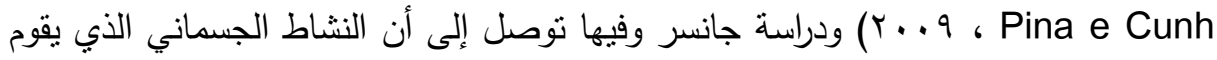

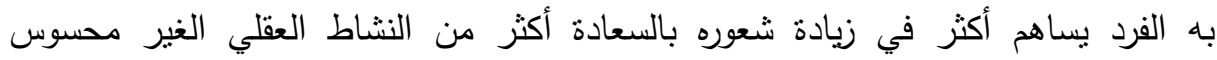

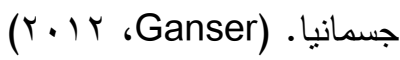

لكنه وفي حدود علم الباحثني، لا توجد دراسة تتاولت بالتفصيل العلاقة الترابطية بينهما،

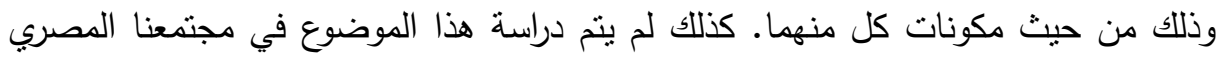
من قبل. لذلك ظهرت الحاجة إلى تغطية هذا الموضوع.

\section{أسئلا الصوراسة}

• ما مدى الارتباط بين قوة الإرادة للأفراد والثعور بالسعادة؟

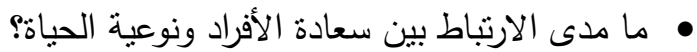

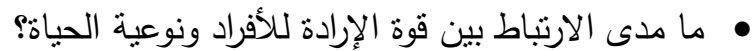

\section{أهساهي التواسمة}

•اكتشاف دور الإرادة في الثعور بالسعادة، ومعرفة شكل العلاقة بينهما. • • تحديد استراتيجيات وآليات تساهم في زيادة الثعور بالسعادة. • تقديم توصيات تساهم في تتمية علم النفس الإيجابي في مصر •

\section{هنوض القراسلة}

الفرض الأول: يوجد فرق دال احصائياً بين منوسط الدرجات التي يحصل عليها المفحوصين على اختبار السعادة باختلاف نوعية الحياة الفرض الثاني: يوجد فرق دال احصائياً بين متوسط الدرجاء بات التي يحصل عليها المفحوصين على اختبار الإرادة والتحكم في الذات باختلاف نوعية الحياة. الفرض الثالث: هناك ارتباط دال احصائياً بين السعادة وقوة الإرادة.

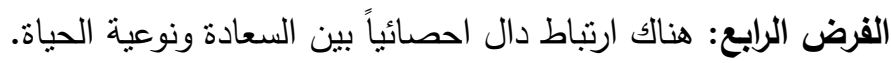
الفرض الخامس: هناك ارتباط دال احصائياً بين قوة الإرادة ونوعية الحياة.

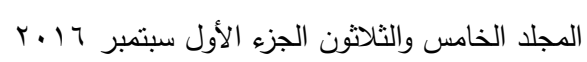




\section{أهمية الصواسمة}

أولاً: أهمية نظرية: لانوجد دراسة في الوطن العربي تتتاول موضوع السعادة والإرادة حتى الآن. والدراسات النفسية العربية في كل من مجال السعادة والإرادة نادرة. لذلك نقدم هذا البحث لتغطية هذه الموضوعات الهامة. تعنبر هذه الدراسة خطوة للأمام في إحدى المجالات الحديثة وهي علم النفس الإيجابي،

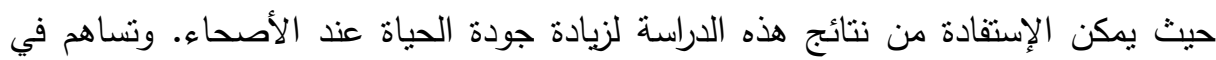
نشر هذا الفرع من العلم في مصر . كما تتضمن هذه المقالة تعريف معنى السعادة ومسبباتها بشكل عام. توفير مقياس للسعادة، وتقديم مقياس جديد للإرادة ويطور فكرة قياس الإرادة بما يتتاسب

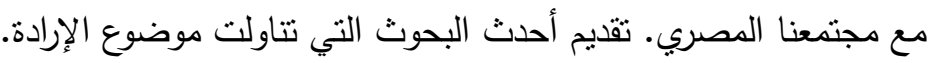
ثانياً: أهمية تطبيقية: هبط مستوى السعادة عند المصريين نتيجة للظروف الاقتصادية والاجتماعية التي نمر بها الآن. هذا أمر نشعر به جميعاً كما أنه جاء في دراسة شبكة حلول

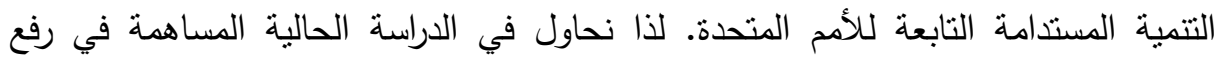
مستوى السعادة عن طريق توضوح الأساليب التي توصل لها العلماء للعمل على ذللك.

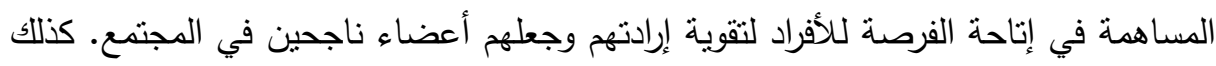

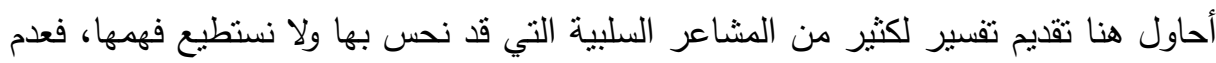
تحقيق الأهداف يمكنه أن السبب في إرسال نلاك الإثارات.

\section{التراسايت المارئية}

كما ذكرنا، فإن الدراسات التي نتاولت كل من الإرادة والسعادة قليلة، لكن نذكر هنا ما

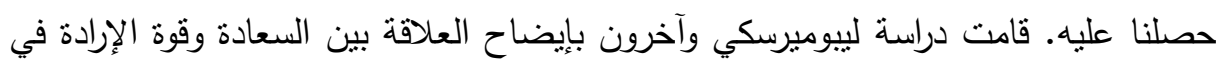

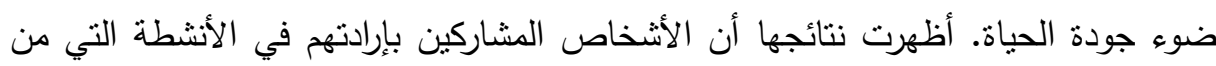

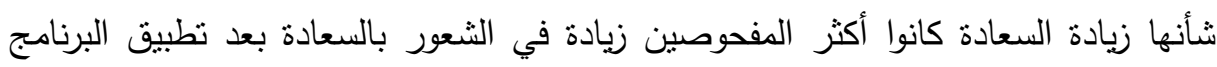

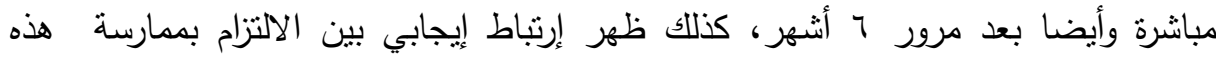
356

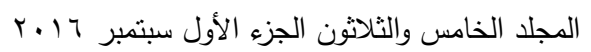




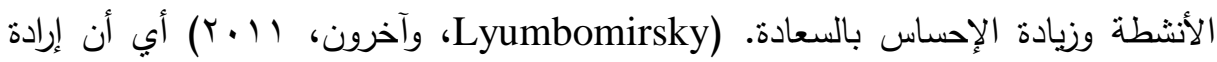

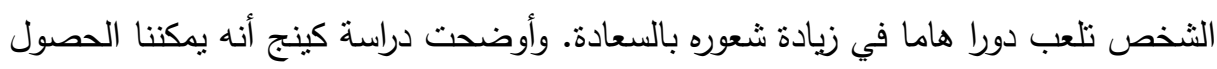

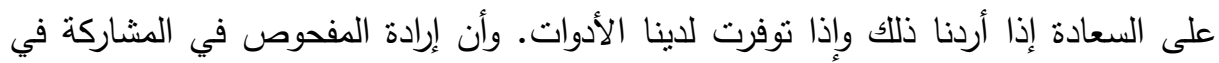

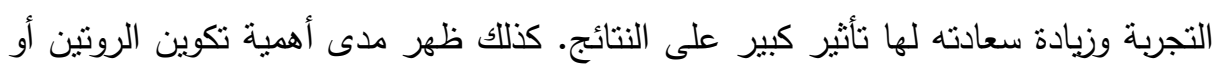

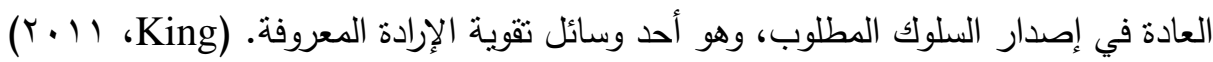

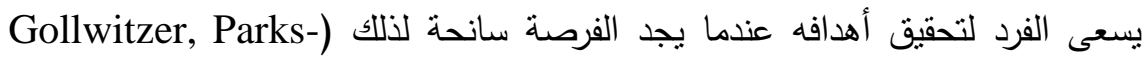
Stamm \& Oettingen

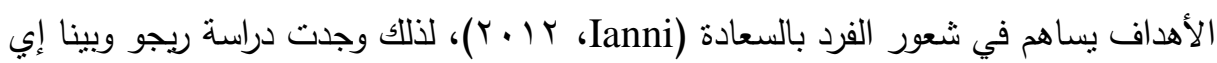
كنه أنه بمجرد إدراك الفرد لوجود هذه الفرصة وبداية العمل في هذا المجال نزيد سعادته. وتحدث لامبرت في دراسته على أن أهم أسباب (r . Rego, \& Pina e Cunh)

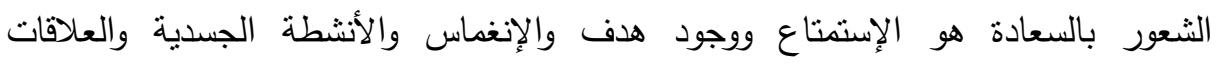

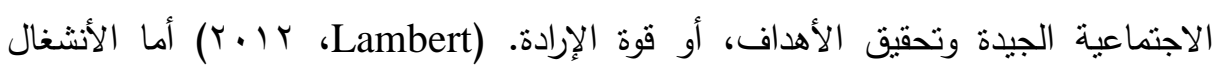
بالفشل الثخصي يقلل من سعادة الفرد، وهذا الانشغال يصاحب أيضا أصحاب الإدة الإرادة الضعيفة ويمنعهم من تحقيق أهدافهم كما جاء في نظرية كوهل. (Diefendorff، وآخرون،

والصحة البدنية الجيدة دليل على جودة الحياة، وفي علاقتها بتحقيق الإرادة وبالتالي زيادة السعادة، أوضحت دراسة جانسر أن النشاط الجسماني الذي يقوم به الفرد بساهم أكثر الإنة

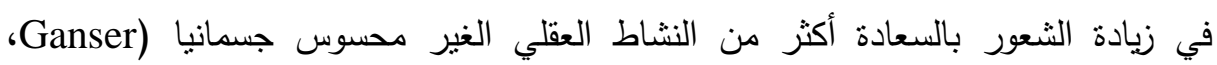

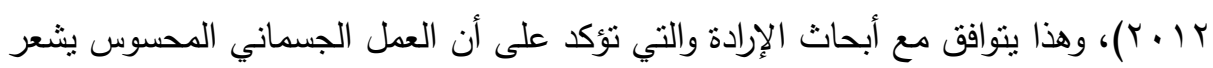

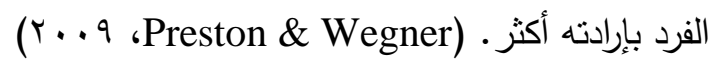




\section{الإلطار اللنظليمه}

إذا نظرنا إلى مستوى السعادة في مصر، نجد أن دراسة شبكة حلول التتمية المستدامة

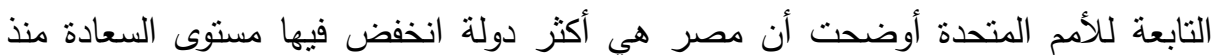

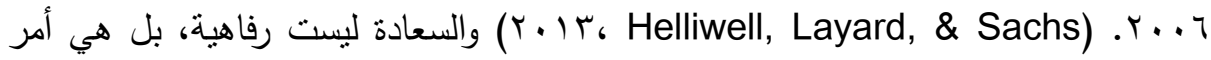

حيوي يؤدي وظائف عظيمة في حياة الفرد. ومن هنا تتبع أهمية الدراسة الحالية.

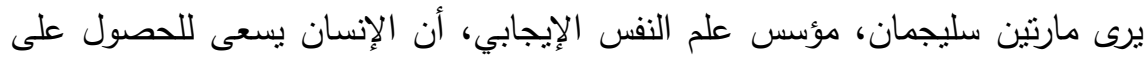
مشاعر إيجابية ويتجنب المشاعر السلبية لأنها تساعد على مجابهة مصاعب الحباة وتحمل الألم وتجعل الفرد يأخد احتباطات السلامة دائماً حين التعرض للخطر، والأهم من ذلك هو لاعل أنها تزيل من آثار المشاعر السلبية. اهتمت أبحاث علم النفس بالمشاعر السلبية كثثرا، لكنها لم تهتم بالمشاعر الإيجابية ووظيفتها، بالرغم من أنها مؤشر جيد لما يحدث في حياة الفرد.

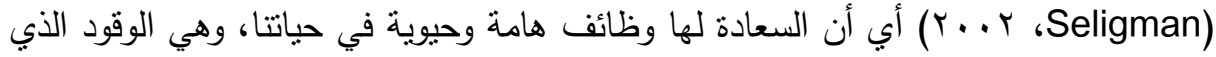
يدفع الفرد للبقاء على قيد الحياة والنجاح فيما يقوم به من أعمال.

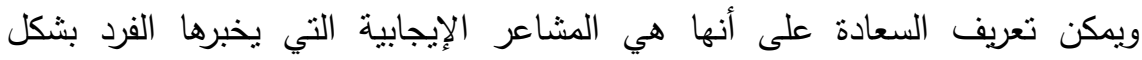

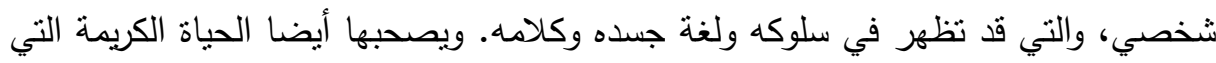
توفر الاحتياجات الأساسية. يساهم هذا في جعل الفرد مقبل على الحياة وناجح فيما يؤديه من ونه أعمال وفي علاقاته مع الآخرين. توجد أدلة علمية على أن وجود مشاعر إيجابية عند الفرد هو أمر يساعد على التتبوء

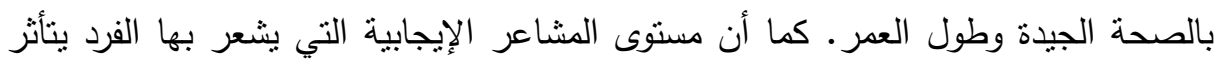

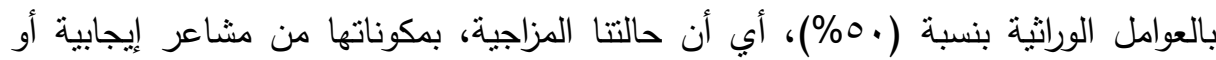

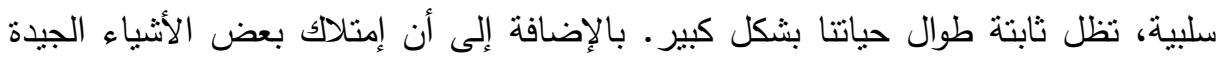

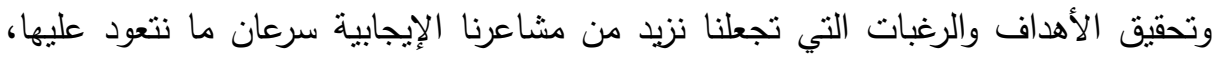

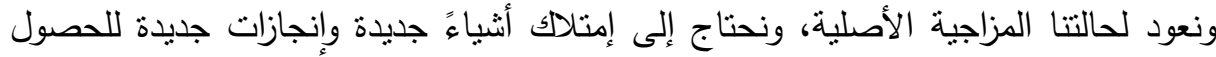
على مشاعر إيجابية مرة ثانية. ووجدت الدراسات أن أحداث الحياة سواء الجيدة أو التي إهاء تحتوى على خسائر كثثرة أو الجمال الظاهري أو الصحة، لا يوجد بينها وبين الشعور بالسعادة الشاد 
ارتباط كبير • إذن نستطيع القول بأن العوامل الوراثية والتعود يحافظان على مستوى السعادة

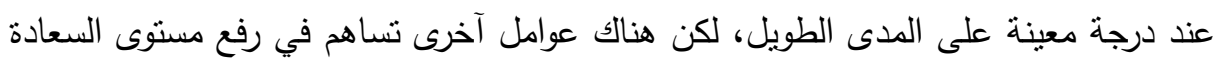

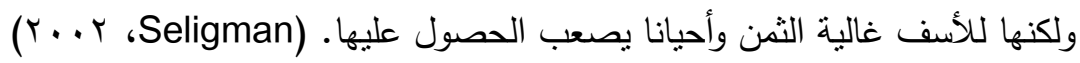
ولكي يحصل الفرد على السعادة، عليه أن يسعى إلى ذللك ويستخدم إرادته، كما أن الوصول إلى الأهداف وتحقيقها يصحبه شعوراً بالسعادة. كما يصحب ذلفي ذلك شعور بالثقة في النفس ويزيد من الصحة النفسية. إن العلاقة بين السعادة وقوة الإرادة علاقة نستحق الدراسة لأن نفعها يعود على الفرد وزيادة إنتاجيته، وبالتالي يستقيد منها المجتمع ككل.

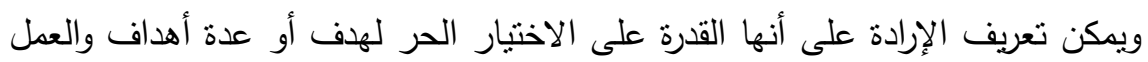
على تحقيقها عن طريق التحكم في الحركة البدنية أو العطليات العقلية إلى إن يتم تحقيق هذاره الأهداف. وهناك علاقة تفاعلية بين العقل والمشاعر، فالأفكار تنؤدي إلى إثارة المشاعر والمشاعر

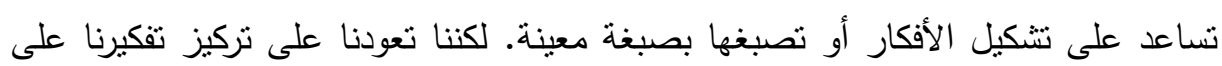

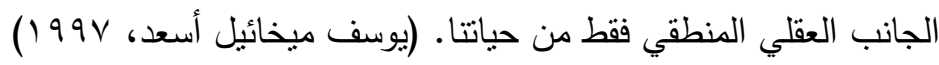
يقيم الثخص نفسه أثناء أداءه للسلوك الإرادي بطريقتين، الأولى هي مقارنة سلوكه

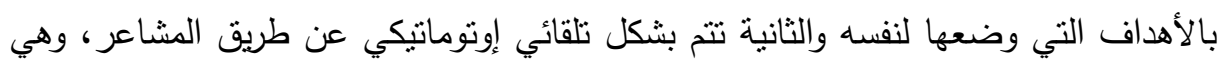

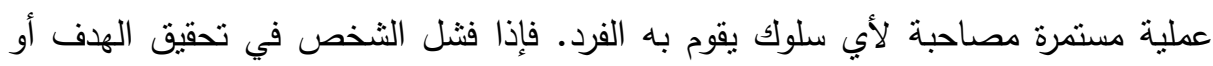

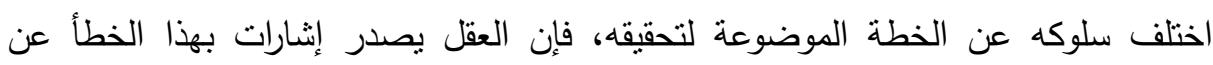

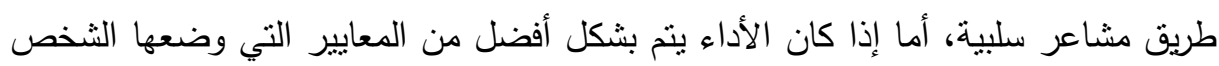

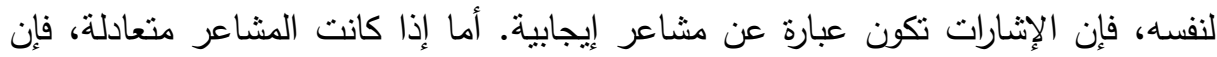

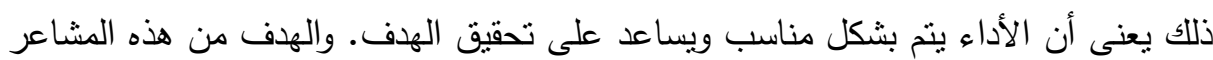

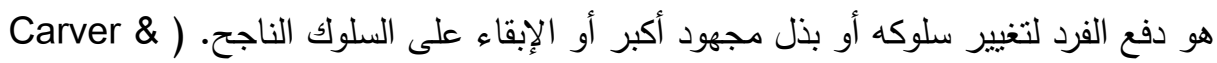
( $r$. . 9 ، Scheier 
وترى الدراسة الحالية أن نوعية الحياة تثمل المستوى الاقتصادي ويتمتل في المستوى التعليمي ومستوى الدخل ومقدار الانفاق على جوانب الحياة المختلفة، ونوعية الحياة البيئية وتتمل خصائص المسكن والمنطقة التي يعيش فيها الفرد. وكذلك نوعية الحياة الصحية

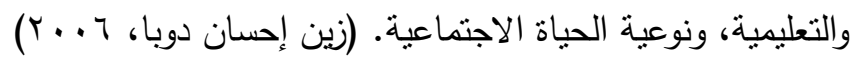

\section{إجزاعايت الصواسما}

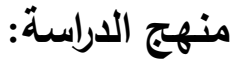

استخدمت الدراسة الحالية المنهج الوصفي، حيث ثم تقديم الاختبارات للفحوصين. ثم

تمت معالجة البيانات باستخدم معامل إرتباط بيرسون ومعامل إرتباط سبيرمان ومعامل الانحدار البسيط واختبار ت وتحليل التباين الاحادي ANOVA والمقارنات الثنائية.

أدوات الدراسة:

() اختبار مؤشرات السعادة، وهو من إعداد الباحثين، ويتكون من (0) عبارة تصف كل

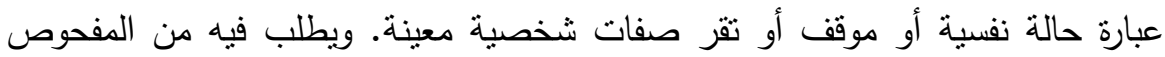
إختيار إحدى الاجابات التالية: غير موافق، أو لا أستطيع التحديد، أو موافق. ويقيس مونه

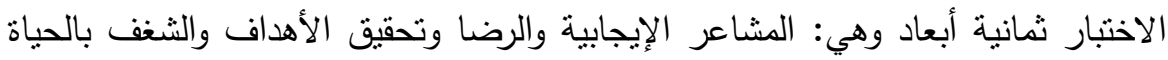

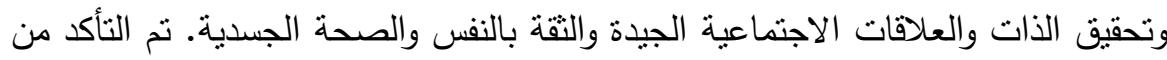
ثبات الاختبار بطريقة إعادة الإجراء، وكانت قيمة معامل الارتباط بين التطبيق الأول

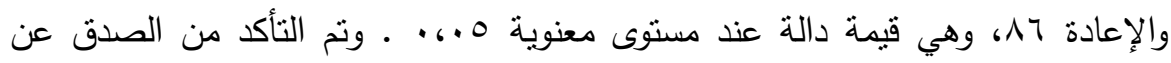
طريق المحكمين وحساب الارتباط بين المقاييس الفرعية والدرجة الكلية، وتراوحت قيم وهيم

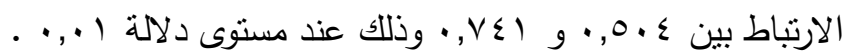

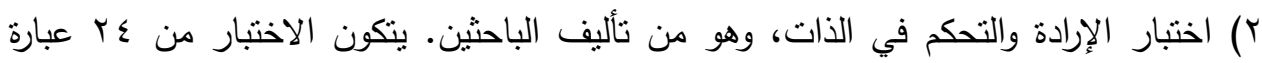

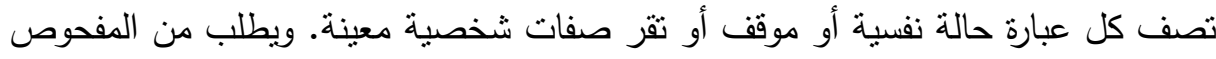

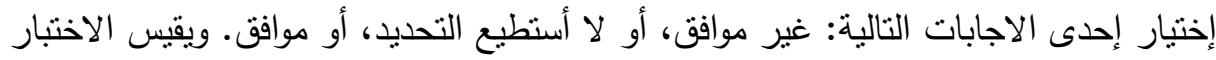
ثلاثة أبعاد وهي الانشغال والوعي بالأهداف والتحكم في الذات. نم التأكد من ثبات الاخدي الاختبار 


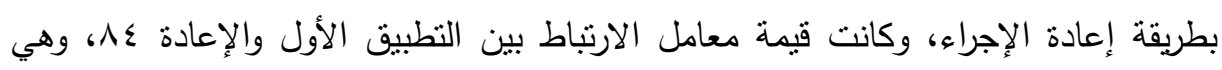

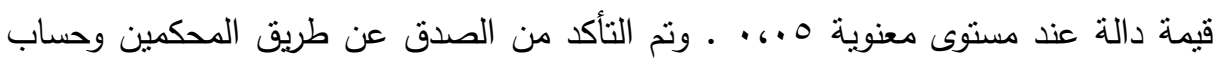

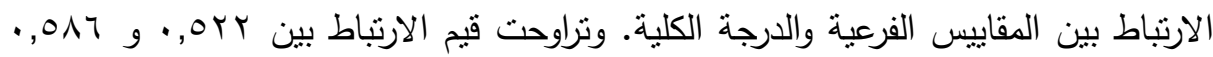

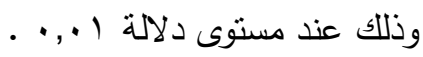
r) استبيان نوعية الحياة، هو مقياس لجودة الحياة أعدته زين إحسن دوبا. (زين إحسان دوبا،

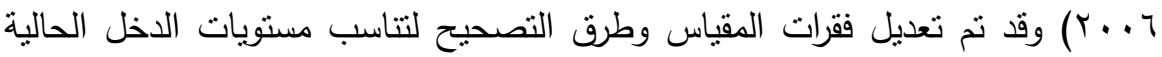
وكذللك غلاء الأسعار • يتكون الاستبيان من 90 بند لقياس المستوى الاقتصادي والتعليمي ومستوى الدخل ومقدار الانفاق على جوانب الحياة المختلفة، ونوعية الحياة البيئية وخصائص المسكن والمنطقة التي يعيش فيها الفرد. وكذلك نوعية الحياة الصحية والتعليمية، ونوعية الحياة الاجتماعية. عينة الاراسة:

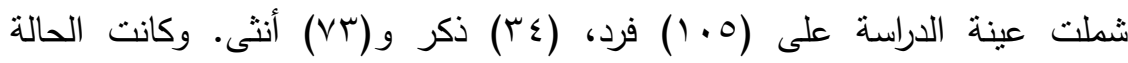

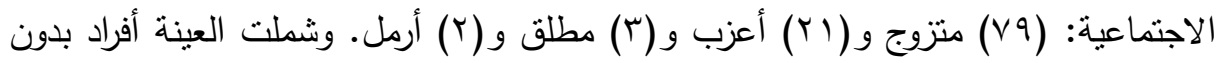

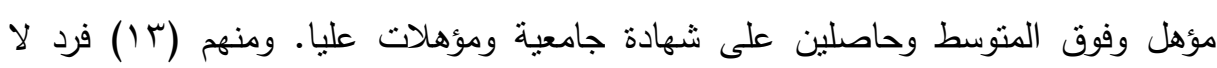

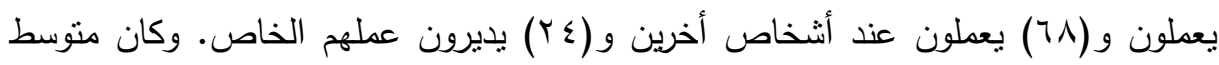

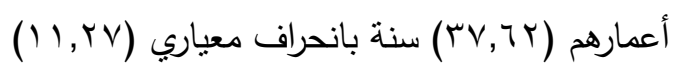
مكان وزمان التطبيق: أجريت الدراسة في القاهرة، عاصمة جمهورية مصر العربية في مناطق السادس من أكتوبر والزيتون في عام 10 ـ ب بين شهري مارس وديسمبر ، وذلك على عينة من المصريين. 


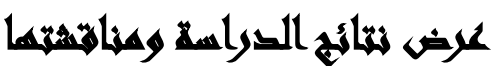

الفرض الأول: للتحقق من صحة الفرض الأول تم استخدام تحليل التباين الاحادي ANOVA جدول(1): الفرق في درجات السعادة باختلاف نوعية الحياة

\begin{tabular}{|c|c|c|c|c|c|c|}
\hline الدلاليةي & "قيمة & المربعات & الحرجية & المربعات & مصدر الاختلاف & المقياس \\
\hline \multirow{3}{*}{ دالة عند } & \multirow{3}{*}{$0, Y 01$} & $110, r \wedge 1$ & r & rM.,Vדr & بين المجموعات & \multirow{3}{*}{ الايجشابيه } \\
\hline & & Y1,9V1 & $1 \cdot r$ & $r Y \leqslant 1, \cdot 10$ & داخل المجموعات & \\
\hline & & & $1 \cdot \varepsilon$ & $r \leqslant V \backslash, \wedge \leqslant \wedge$ & المجموع & \\
\hline \multirow{3}{*}{ 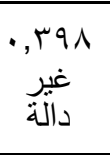 } & \multirow{3}{*}{$\cdot, 9 \mu}$. & $0, Y M T$ & $r$ & $1 \cdot, 577$ & بين المجموعات & \multirow{3}{*}{ الرضا } \\
\hline & & $0, \pi Y \wedge$ & $1 \cdot r$ & $0 \leqslant 1,+7 V$ & داخل المجموعات & \\
\hline & & & $1 \cdot \varepsilon$ & 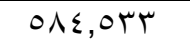 & المجموع & \\
\hline \multirow{3}{*}{ 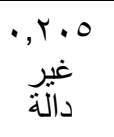 } & \multirow{3}{*}{$1,7 \cdot V$} & $9, \leq 7 Y$ & r & $1 \wedge, 9 Y \varepsilon$ & بين المجموعات & \multirow{3}{*}{ الاهدافتيث } \\
\hline & & $0, \wedge \wedge \vee$ & $1 \cdot r$ & $7 \ldots, 577$ & داخل المجموعات & \\
\hline & & & $1 \cdot \varepsilon$ & $719,19$. & المجموع & \\
\hline \multirow{3}{*}{ 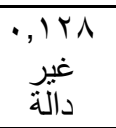 } & \multirow{3}{*}{$r, 1 \cdot 1$} & $Y \cdot, 70$. & $r$ & $\varepsilon 1, \Gamma \ldots$ & بين المجموعات & \multirow{3}{*}{ الشغف } \\
\hline & & q,AMI & $1 \cdot r$ & $1 \cdots Y, V O V$ & داخل المجموعات & \\
\hline & & & $1 \cdot \varepsilon$ & $1 . \varepsilon \varepsilon, .0 \mathrm{~V}$ & المجموع & \\
\hline \multirow{3}{*}{ ع ع +, • } & \multirow{3}{*}{ ґ,人тq } & 9,190 & $r$ & $1 \wedge, 1 \wedge 9$ & بين المجموعات & \multirow{3}{*}{ تحقيق } \\
\hline & & Y,rVT & $1 \cdot r$ & $r \leq Y, r V T$ & داخل المجموعات & \\
\hline & & & $1 \cdot \varepsilon$ & rT.,Vדr & المجموع & \\
\hline \multirow{3}{*}{ 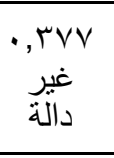 } & \multirow{3}{*}{$\cdot, 9 \wedge 7$} & 8,199 & $r$ & $\Lambda, r q 9$ & بين المجموعات & \multirow{3}{*}{ الاجنماعيه } \\
\hline & & $\varepsilon, Y \circ q$ & $1 \cdot r$ & $\varepsilon \Gamma \varepsilon, \varepsilon 09$ & داخل المجموعات & \\
\hline & & & $1 \cdot \varepsilon$ & $\varepsilon \leqslant Y, \wedge \circ V$ & المجموع & \\
\hline \multirow{3}{*}{ 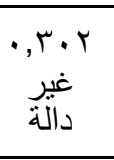 } & \multirow{3}{*}{$1, Y \backslash 1$} & $0,1 Y V$ & $r$ & $1 \cdot, Y 0 \leq$ & بين المجموعات & \multirow{3}{*}{ النقسه فى } \\
\hline & & $\varepsilon, Y T_{0}$ & $1 \cdot r$ & $\varepsilon r 1,9 \mu v$ & داخل المجموعات & \\
\hline & & & $1 \cdot \varepsilon$ & $\varepsilon \leq r, 19$. & المجموع & \\
\hline \multirow{3}{*}{ غير } & \multirow{3}{*}{$\cdot, 7 \cdot 1$} & $\cdot, 9 \leq 9$ & $\bar{r}$ & $1, \wedge 9 \mathrm{~V}$ & بين المجموعات & \multirow{3}{*}{ الجسديه } \\
\hline & & $1,07$. & $1 \cdot r$ & $109, .94$ & داخل المجموعات & \\
\hline & & & $1 \cdot \varepsilon$ & $17 ., 99$. & المجموع & \\
\hline \multirow{3}{*}{ دالة عند , د } & \multirow{3}{*}{ r,q4 } & VVY,T70 & $r$ & $10 \leqslant 0, \pi r$. & بين المجموعات & \multirow{3}{*}{ الكلية } \\
\hline & & 197,079 & $1 \cdot r$ & $Y \ldots 0 \cdot, 71$ & داخل المجموعات & \\
\hline & & & $1 \cdot \varepsilon$ & r1090,rq. & المجموع & \\
\hline
\end{tabular}


أظهرت نتائج الجدول السابق عدم وجود فرق دال إحصائياً بين متوسط درجات السعادة

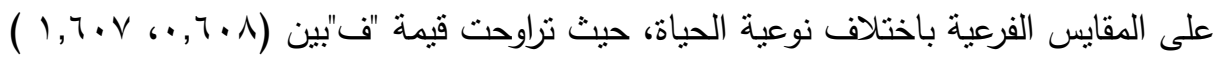

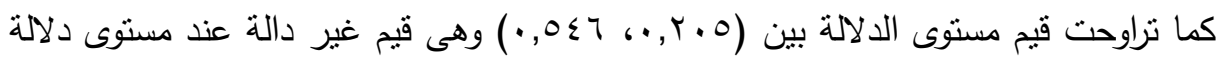

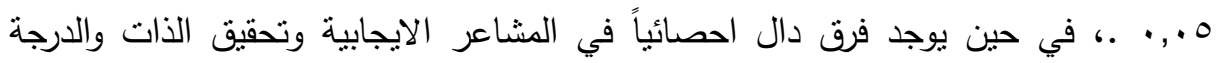

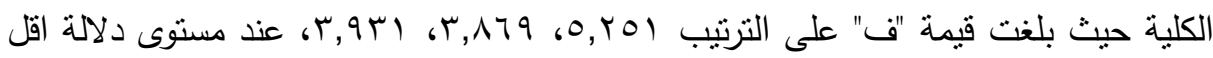
من 0

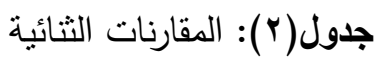

\begin{tabular}{|c|c|c|c|c|}
\hline \multicolumn{3}{|c|}{ الفرق بين المتوسطات } & \multirow{2}{*}{ مجموعة المقارنة } & \\
\hline مرتفع & متوسط & منخفض & & \\
\hline & & - & منخفض & \multirow{3}{*}{ المشاعر الايجابية } \\
\hline & - & $r, \cdot r \varepsilon-$ & متوسط & \\
\hline \multirow[t]{7}{*}{-} & $1,07 Y-$ & $* r, 097-$ & مرتفع & \\
\hline & & & منخفض & \multirow{3}{*}{ تحقيق الذات } \\
\hline & & $\cdot, 09 Y-$ & متوسط & \\
\hline & $\cdot, \Sigma Y Y-$ & $* 1, \cdot 10-$ & 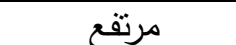 & \\
\hline & & & منخفض & \multirow{3}{*}{ الدرجة الكلية } \\
\hline & & $\varepsilon, \vee \wedge \varepsilon-$ & متوسط & \\
\hline & $\varepsilon, 0, Y-$ & $* q, r \wedge \vee-$ & مرتفع & \\
\hline
\end{tabular}

| = دالة عند •, •

تشير بيانات الجدول السابق الى ان الاختلاف في المشاعر الايجابية وتحقيق الذات و

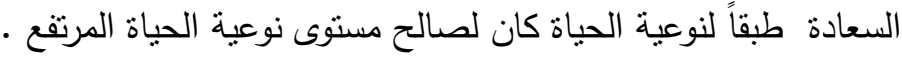


الفرض الثاني: للتحقق من صحة الفرض الثاني تم استخدام تحليل التباين الاحادي ANOVA

جدول(r): الفرق في درجات قوة الإرادة باختلاف نوعية الحياة

\begin{tabular}{|c|c|c|c|c|c|c|}
\hline مستوى الدلالة & "قيمة & المربعات & الحرية & المربعات & مصدر الاختلاف & المقياس \\
\hline \multirow{3}{*}{ 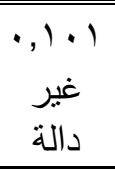 } & \multirow{3}{*}{$r, r \leqslant V$} & $\varepsilon \cdot, 7 \leqslant q$ & r & $\wedge 1, r q \Lambda$ & بين المجموعات & \multirow{3}{*}{ الالنشغال } \\
\hline & & IV,rYY & $1 \cdot r$ & IV74,人ro & داخل المجموعات & \\
\hline & & & $1 \cdot \varepsilon$ & $1 \wedge \varepsilon \wedge, 1 \Gamma \mu$ & المجموع & \\
\hline \multirow{3}{*}{ 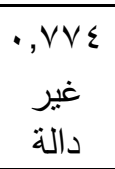 } & \multirow{3}{*}{$\cdot, r \circ V$} & $\cdot, \varepsilon .0$ & $r$ & $\cdot, \wedge \cdot 9$ & بين المجموعات & \multirow{3}{*}{ بالاهداف } \\
\hline & & $1,0 \vee 7$ & $1 \cdot r$ & $17 \cdot$, VOr & داخل المجموعات & \\
\hline & & & $1 \cdot \varepsilon$ & 171,074 & المجموع & \\
\hline \multirow{3}{*}{ 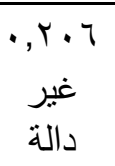 } & \multirow{3}{*}{$1,7 \cdot r$} & $\varepsilon \cdot$, \&Ar & $r$ & $\Lambda \cdot, V T V$ & بين المجموعات & \multirow{3}{*}{ التاتم فى } \\
\hline & & YO,Y.Y & $1 . r$ & roV.,TrE & داخل المجموعات & \\
\hline & & & $1 \cdot \varepsilon$ & r701,rq. & المجموع & \\
\hline \multirow{3}{*}{ • } & \multirow{3}{*}{ 1,9ז0 } & $I \leqslant 7, \Gamma \vee r$ & $r$ & $r q r, V \leqslant 0$ & بين المجموعات & \multirow{3}{*}{ الكلية } \\
\hline & & $V 0,707$ & $1 \cdot r$ & $V I V 7,91 Y$ & داخل المجموعات & \\
\hline & & & $1 \cdot \varepsilon$ & $1 \ldots 9,70 \mathrm{~V}$ & المجموع & \\
\hline
\end{tabular}

أظهرت نتائج الجدول السابق عدم وجود فرق دال إحصائياً بين متوسط درجات الإرادة والتحكم في الذات باختلاف نوعية الحياة على الدرجة الكلية والمقاييس الفرعية، حيث بلغت

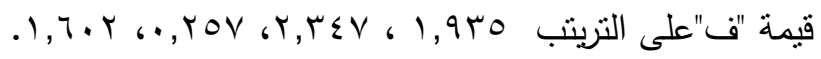

الفرض الثالث: للتحقق من صحة الفرض الثالث تم استخدام معامل ارتباط بيرسون لمعرفة دلالة العلاقة بين السعادة وقوة الإرادة والجدول التالي يوضح ذللك: 
أحمد مصطفى العتيق وآخرون

جدول(ع): قيمة معامل الارتباط بين السعادة وقوة الإرادة ومستوى الدلالة

\begin{tabular}{|c|c|c|c|c|}
\hline الارجة الكلية & في الذات & الوعى بالاهداف & الانشغال بالأكار & \\
\hline 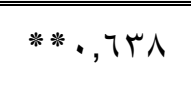 & $* *, 0,1$ & $* *,, \leq Y V$ & $* * ., 099$ & الإيجابيه \\
\hline$* *$, * $\leqslant 01$ & ***, , ฯ & ** • , & $* *,, \Sigma I V$ & الرضا \\
\hline$* *, \varepsilon \wedge q$ & 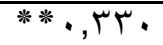 & $* *,, Y 99$ & $* *, 0 \leqslant \wedge$ & تحقيق الاهداف \\
\hline **, OYO & $\left.*_{*}^{*} \cdot, r q\right)$ & ***, $ґ \wedge q$ & $* * 0.7$ & الثغف بالحياة \\
\hline ***, $\_\cdot \Lambda$ & ***, & *., YY & $* *, \Gamma \vee \varepsilon$ & تحقيق الدات \\
\hline rq & $* *$ & $\varphi, 1 \geq z$ & * & $\begin{array}{c}\text { الاجناقاعيه } \\
\text { الاجناتهات }\end{array}$ \\
\hline ***, $\Gamma \leq \Lambda$ & $* *, Y \wedge V$ & *, & ***,,$\Gamma \cdot \Lambda$ & الثقه في النفس \\
\hline **, & $* *$ & $\cdot, 10$. & $* *, \varepsilon r$. & الجسديه \\
\hline ***, TVY & ***,OYI & $* *,, \S \leqslant 1$ & $* *,, 7 \leq 9$ & الدرجة الكلية \\
\hline
\end{tabular}

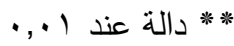

* دالة عند 0., .

يتضح من بيانات الجدول السابق: - وجود علاقة ارتباط دالة احصائياً بين السعادة وقوة الإرادة الدرجة الكلية وابعادها،حيث

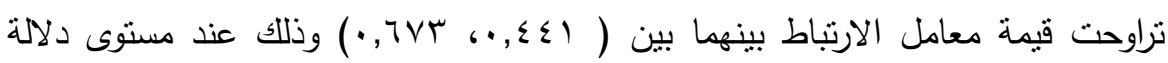
$\cdot(\cdot, \cdot 1)$

- وجود علاقة ارتباط دالة احصائياً بين المشاعر الايجابية وقوة الإرادة الدرجة الكلية

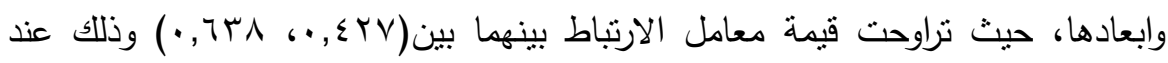

$$
\text { مستوى دلالة (1 (., (•). }
$$

- وجود علاقة ارتباط دالة احصائياً بين الرضا وقوة الإرادة الدرجة الكلية وابعادها،حيث

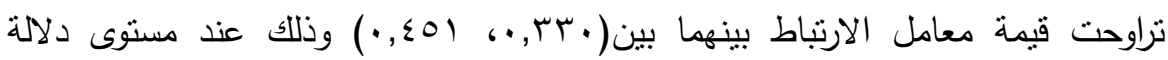

$$
\cdot(\cdot, \cdot)
$$

- وجود علاقة ارتباط دالة احصائياً بين تحقيق الاهداف وقوة الإرادة الدرجة الكلية وابعادها،

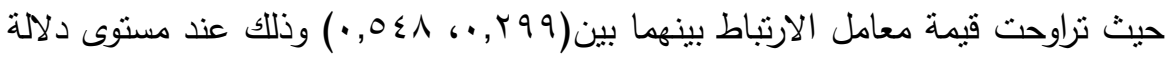
$\cdot(\cdot, \cdot 1)$ 
- وجود علاقة ارتباط دالة احصائياً بين الثغف وقوة الإرادة الدرجة الكلية وابعادها، حيث

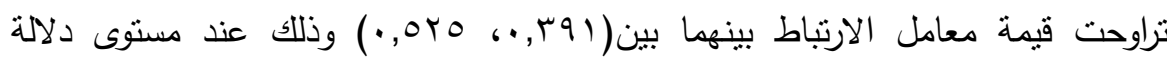

$$
\cdot(\cdot, \cdot 1)
$$

- وجود علاقة ارتباط دالة احصائياً بين تحقيق الذات وقوة الإرادة الدرجة الكلية وابعادها،

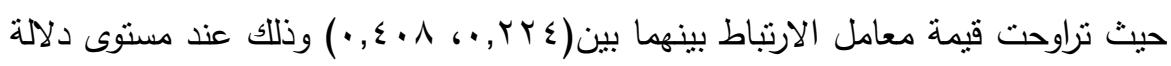

$$
\cdot(\cdot, \cdot 1) \text { و (•,. }(\cdot 0)
$$

- وجود علاقة ارتباط دالة احصائياً بين العلاقات الاجتماعية وقوة الإرادة الدرجة الكلية

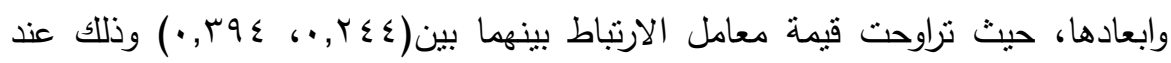

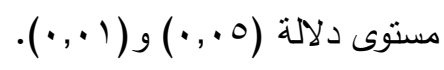

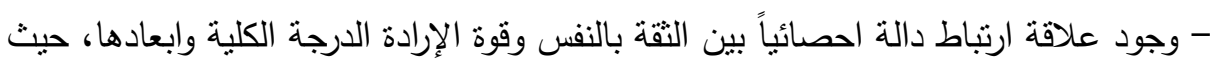

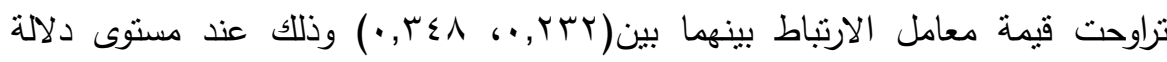

$$
\cdot(\cdot, \cdot)(\cdot, \cdot 0)
$$

- وجود علاقة ارتباط دالة احصائياً بين الصحه الجسديه وقوة الإرادة الدرجة الكلية وابعادها،

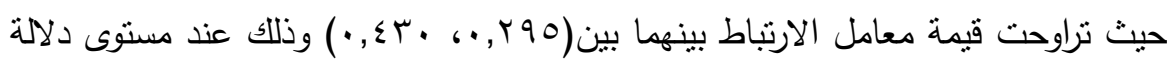

$$
\cdot(\cdot, \cdot 1)
$$

ولمعرفة نسبة الثأثير نم استخدام تحليل الانحدار البسيط والجدول التالي يوضح ذلك: 
أحمد مصطفى العتيق وآخرون

جدول(•): نتائج الانحدار

\begin{tabular}{|c|c|c|c|c|c|c|c|c|}
\hline 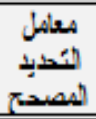 & لمعالدل & 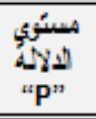 & قَبنة فت & 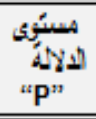 & 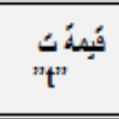 & 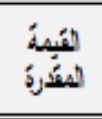 & لهنتفير للهسئك" & 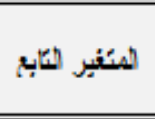 \\
\hline \multirow{4}{*}{,$+ \varepsilon+0$} & \multirow{4}{*}{,$+ \varepsilon T Y$} & \multirow{4}{*}{,++} & \multirow{4}{*}{$T \&, 00 T$} &.,$+\pi T$ & rilvo & 0,101 & الثابت & \multirow{4}{*}{ الإليجانيبة } \\
\hline & & & & $\cdot,+$ & $\varepsilon, १ १ १$ &., $01 \varepsilon$ & بالافكئز الفيلبية & \\
\hline & & & & וזי & $1, \pi า \varepsilon$ &., 871 & الوعرب، بالاهداف & \\
\hline & & & &.,+19 & $r,+14$ &.,$T+1$ & النحكم في الذات & \\
\hline \multirow{3}{*}{., 19.} & \multirow{3}{*}{,$+ T+T$} & \multirow{3}{*}{$+\cdots$} & \multirow{3}{*}{ IT, } &.,$+V T$ & $1,1,9$ & $r, \varepsilon V\}$ & الأنبث & \multirow{3}{*}{ الزرضا: } \\
\hline & & & &.,$+r$ & $r, \cdot V T$ & רעו, & بالافكئز السلبية & \\
\hline & & & &.,$+\varepsilon 7$ & $r,+17$ &,$++9 V$ & النحكم في الذات & \\
\hline \multirow{4}{*}{$\cdot, T A V$} & \multirow{4}{*}{$\cdot, r+V$} & \multirow{4}{*}{,$+ \cdots$} & \multirow{4}{*}{$1 \varepsilon, 9 \varepsilon \varepsilon$} & $\cdot,+\cdot$ & $7,1 \& 7$ & $\Lambda, 1 \varepsilon$. & | & \multirow{4}{*}{ نَحسيُقِ الاهداف } \\
\hline & & & & $\cdot, \cdot$ & $0,1 \varepsilon \varepsilon$ & . r r. & 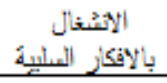 & \\
\hline & & & &., $0 Y \varepsilon$ & . &., $1 T$. & الوعرب بالالداف & \\
\hline & & & &.,$V Y !$ &.,$\pi 01$ &.,+19 & النحكم في الألك & \\
\hline \multirow{3}{*}{$\cdot, Y \wedge)$} & \multirow{3}{*}{, Тव\& } & \multirow{3}{*}{,$+\cdots$} & \multirow{3}{*}{ 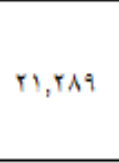 } & $\cdot,+\cdot$ & $\mathrm{V}, \mathrm{qrT}$ & $1, \mathrm{~A} 1 \mathrm{~V}$ & النانبت & \multirow{3}{*}{ النُفف } \\
\hline & & & &,$+ \cdot$ & $\varepsilon, 0 \leqslant 7$ & יTIT & بالانكائشغالسلبية & \\
\hline & & & &,$++Y !$ & $r, r \varepsilon 7$ &., $0 \leqslant 7$ & الوع بـ بالانداف & \\
\hline \multirow[b]{2}{*}{ זTוני } & \multirow[b]{2}{*}{., $1 \varepsilon}$. & \multirow[b]{2}{*}{,$+\cdots$} & \multirow[b]{2}{*}{17,500} &,$++\cdots$ & $9, \varepsilon+r$ & $T, V \varepsilon T$ & النابت & \multirow[b]{2}{*}{ نَحِيَُّ الدات } \\
\hline & & & & $\cdot, \cdot$ & $\varepsilon,+9 T$ & $0,1 \leqslant 1$ & بالافكاز الشيلبية & \\
\hline \multirow[b]{2}{*}{.119} & \multirow[b]{2}{*}{.,ITV } & \multirow[b]{2}{*}{,++} & \multirow[b]{2}{*}{$10,+\varepsilon 1$} &,++ & IT,TAV & 11,071 & الثابث & \multirow{2}{*}{ الأجئما عباته } \\
\hline & & & &,$\cdot+$ & 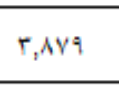 & ivo & بالأفكاز الشيلبية & \\
\hline \multirow[b]{2}{*}{ די人, } & \multirow[b]{2}{*}{$\because+90$} & & & $\cdot,+\cdots$ & $9,11$. & $\Lambda, V T V$ & النابت & \\
\hline & &,++1 & $1+, \times \wedge 7$ &,+++1 & $T, T \wedge \varepsilon$ &., 101 & بالافكز الشيلبية & الثثنه في، النفس \\
\hline & & & &,,$+\cdot$ & $r, \wedge \vee V$ & T,ITV & |نأنبي & \\
\hline .,IVV &., 110 & $\cdot,+$ & הT, & $\cdot, \cdot$ & $\varepsilon, A T T$ & , ITV & بالافكئز السنبلية & الجنبية \\
\hline & & & &,++ & $\gamma, r v i$ & 89,19 & الأبتب & \\
\hline,$+ \varepsilon 7 T$ &,$+ \varepsilon V T$ & $\cdot, \cdots$ & $\{0,0\}$ & $\cdot, \cdot$ & $T, Y T$. & $1, \mathrm{VP}$ & 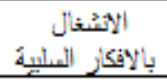 & اللدرجة الكلية \\
\hline & & & &,$++r$ & rilrv &.,$V \varepsilon T$ & النحكر, في الأك & \\
\hline
\end{tabular}

المجلد الخامس والثلاثون الجزء الأول سبتمبر 17 ـ 


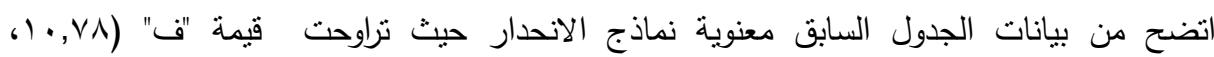
و

•الانشغال بالافكارالسلبية والوعى بالاهداف والتحكم فى الذات يؤثروا على المشاعر

$$
\text { الايجابيه بنسبة (0, • ع \%) }
$$

الانشغال بالافكارالسلبية والتحكم فى الذات يؤثروا على الرضا بنسبة ( ,9 (1\%)

الانشغال بالافكارالسلبية يؤثر على تحقيق الاهداف بنسبة ( Y,V

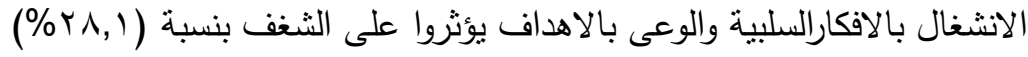

الانشغال بالافكارالسلبية يؤثر على تحقيق الذات بنسبة (r,r (\%)

الانشغال بالافكارالسلبية يؤثرعلى العلاقات الاجنماعيه بنسبة (9, 1 ( 1 (

الانشغال بالافكارالسلبية يؤثرعلى الثقه فى النفس بنسبة (7, 7\%)

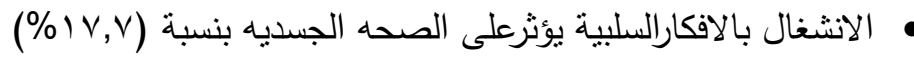

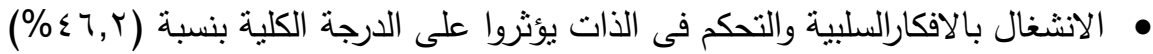
الفرض الرابع: للتحقق من صحة الفرض الرابع تم استخدام معامل ارتباط بيرسون لمعرفة دلالة العلاقة بين السعادة ونوعية الحياة والجدول التالي يوضح ذللك جدول(7): قيمة معامل الارتباط بين السعادة ونوعية الحياة ومستوى الدلالة

\begin{tabular}{|c|c|c|}
\hline \multicolumn{2}{|c|}{ نوعية الحياة } & \multirow[b]{2}{*}{ الشعورالسعادة } \\
\hline قيمة معامل الارتباط & مستوى الدلالة & \\
\hline دالة عند 1 .,. & $\cdot, Y 01$ & المشاعر الايجابيه \\
\hline 1, ه, • غير دالة &., .01 & الرضا \\
\hline r 9 , • غير دالة & $\cdot, I Y A$ & تحقيق الاهداف \\
\hline 79 197 , غ غير دالة & $\cdot, I Y V$ & الثغف \\
\hline دالة عند ا +., & $\cdot, Y 7 \varepsilon$ & تحقيق الذات \\
\hline ا וץ, • غير دالة & $\cdot, .91$ & العلاقات الاجتماعيه \\
\hline س • , • غير دالة & $\cdot, 1 \vee 7$ & التقه في النفس \\
\hline 7ا §, · غير دالة & $\cdot, \wedge$. & الصحه الجسديه \\
\hline دالة عند 0 . , . & $\cdot, r 19$ & الدرجة الكلية \\
\hline
\end{tabular}


يتضح من بيانات الجدول السابق:

• وجود علاقة ارتباط دالة احصائياً بين نوعية الحياة وكل من المشاعر الايجابية وتحقيق لانيق

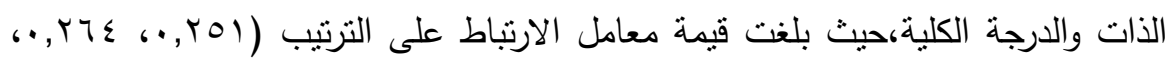

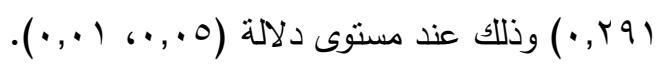

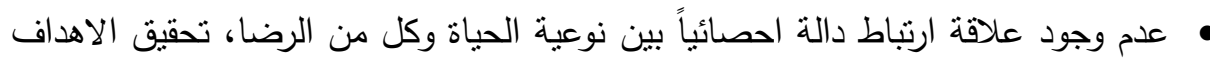
والثغف والعلاقات الاجتماعية والثقة بالنفس والصحة الجسدية،حيث تراوحت قيمة معامل

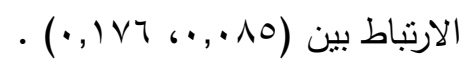

\begin{tabular}{|c|c|c|c|c|c|c|c|c|}
\hline المصحيد & التصليد & "الدستوي & قيمة قَت & "الدلائوي & قيمة ت "t" & القِيمة & المستقلي & التابعير \\
\hline \multirow[b]{2}{*}{$\cdot, .0 \leqslant$} & \multirow[b]{2}{*}{ זT +,. } & \multirow[b]{2}{*}{$\cdot, \cdot 1$} & \multirow[b]{2}{*}{$7, q \cdot V$} & $\cdot, \ldots$ & $9, \cdot \Gamma 1$ & $1 \wedge, 77 \wedge$ & الثابت & \multirow{2}{*}{ الايجابيه } \\
\hline & & & & • & $r, T r A$ & $\cdot, \cdot \mu_{1}$ & الحودة & \\
\hline \multirow[b]{2}{*}{$\cdot, \cdot 7$} & \multirow[b]{2}{*}{$\cdot, \cdot \vee \cdot$} & \multirow[b]{2}{*}{$\cdot, \cdots v$} & \multirow[b]{2}{*}{$V, 797$} & $\cdots$ & $11,7 \vee 7$ & $\vee, \wedge l$. & الثابت & \multirow{2}{*}{ تلذقيق } \\
\hline & & & & $\cdot, \cdots V$ & $r, V V \varepsilon$ & $\cdot, .11$ & الحودة & \\
\hline \multirow[b]{2}{*}{$\cdot, \cdot r q$} & \multirow[b]{2}{*}{$\cdot, \cdot \leq \wedge$} & \multirow[b]{2}{*}{., , YO } & \multirow[b]{2}{*}{$0,19 \varepsilon$} & & 10,294 & 90,199 & الثابت & \multirow{2}{*}{ الكلية } \\
\hline & & & & & Y, YVq & $\cdot, \cdot \wedge$. & الحياة & \\
\hline
\end{tabular}

اتضح من بيانات الجدول السابق معنوية نماذج الانحدار حيث نراوحت قيمة "ف"بين

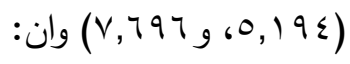

• جودة الحياة تؤثر على المشاعر الايجابيه بنسبة (؟,0\%)

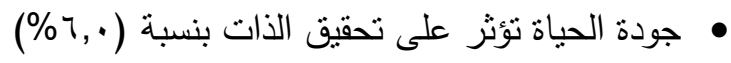

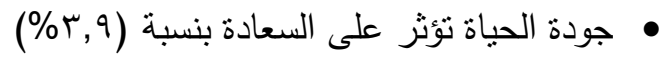


الفرض الخامس: للتحقق من صحة الفرض الخامس نم استخدام معامل ارتباط بيرسون لمعرفة دلالة العلاقة بين قوة الإرادة ونوعية الحياة والجدول النالي يوضح ذلك جدول(^): قيمة معامل الارتباط بين الإرادة ونوعية الحياة ومستوى الدلالة

\begin{tabular}{|c|c|c|}
\hline \multicolumn{2}{|c|}{ نوعية الحياة } & \multirow[b]{2}{*}{ قوة الارادة } \\
\hline مستوى الدلالة & مستوى الدلالة & \\
\hline • r ا, • غير دالة &., 104 & الانشغال بالافكار السلبية \\
\hline 919 9 • غير دالة & $\cdot, \ldots 1$ & الوعى بالاهداف \\
\hline 9 • 7 , • غير دالة &., .01 & التحكم في الذات \\
\hline Vד Y, • غير دالة &., $1 \cdot 9$ & الدرجة الكلية \\
\hline
\end{tabular}

يتضح من بيانات الجدول السابق عدم وجود علاقة ارتباط دالة احصائياً بين قوة الارادة

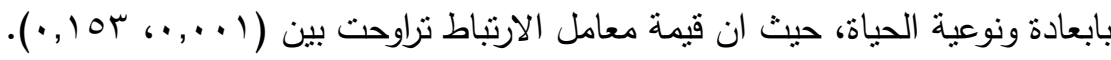

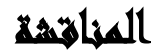

الفرض الأول: يوجد فرق دال احصائياً بين منوسط درجات السعادة باختلاف نوعية الحياة. تم تقسيم الأفراد حسب نوعية الحياة إلى ثلاثة طبقات: منخفضة ومنوسطة ومرتفعة. واتضح أن المنتمين إلى الطبقة المرتفعة تزيد عندهم مؤشرات السعادة بشكل عام والمشاعر لهرد

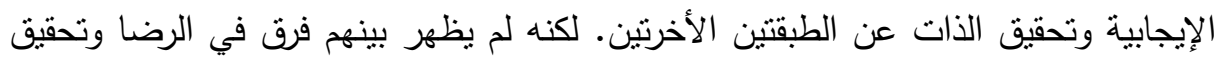
الأهداف والثغف بالحياة والعلاقات الاجتماعية والثقة في النفس والصحة الجسدية.

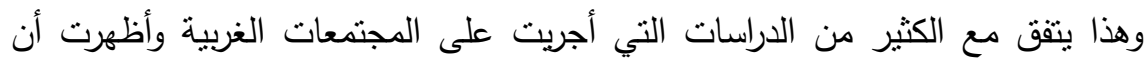
نوعية الحياة لها تأثثر على الثعور بالسعادة منل دراسة شبكة حلول التتمية المستدامة التابعة

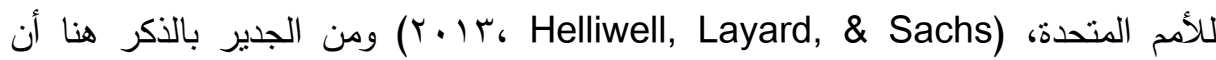
دراسة هيئة الأمم المتحدة قد أقرت أن جودة الحياة البيئية لا تشمل المستوى الاقتصادي فقط، بادئ بل تعتمد أيضاً على الحالة الصحية ووجود أثنخاص مقربين يُعتمد عليهم والحرية في إنخاذ القرارت المصيرية والخلو من الفساد والكرم. ولذلك حرصت على أن يشمل مقياس مؤشرات 
السعادة عدة عوامل بالإضافة إلى المشاعر الإيجابية. وكذلك شمل اختبار نوعية الحياة على عدة عوامل بالإضافة إلى الدخل المادي.

أما العوامل التي لم يظهر فرق بينها عند الطبقات المختلفة فترجع إلى طبيعة الحياة التي

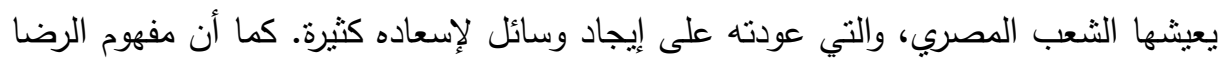

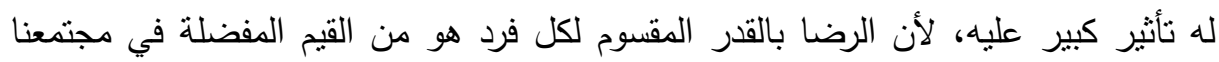

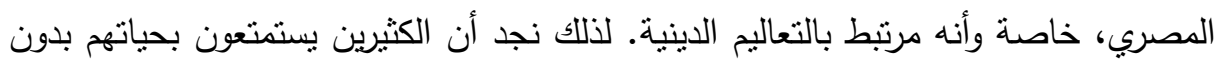

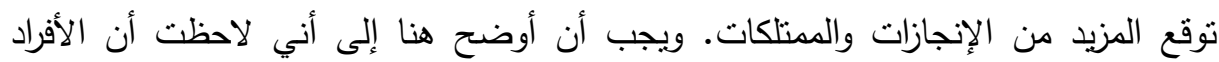

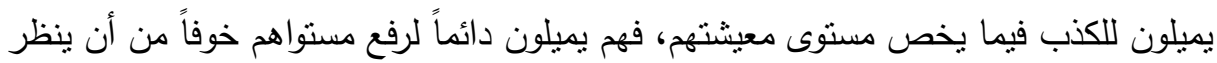
إليهم أحد نظرة دونية. لذلك قد تكون درجاتهم على اختبار نوعية الحياة ليست بالدقة الكافية.

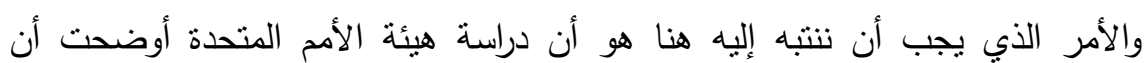
السعادة هي التي تؤثر على السمات السلوكية مثل الابداع والنجاح الاجتماعي والعادات

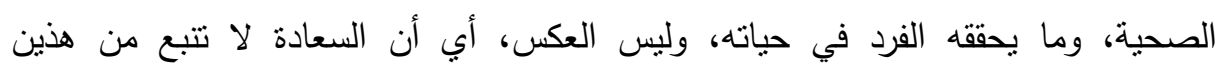

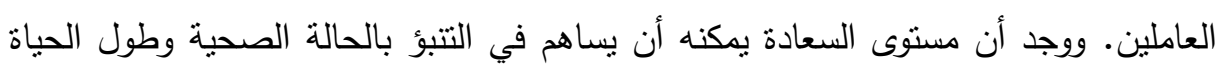

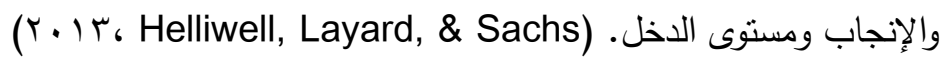
وهذا يتفق مع دراسة جامعة هارفارد التي أوضحت أن هناك عوامل أخرى هامة، وليس

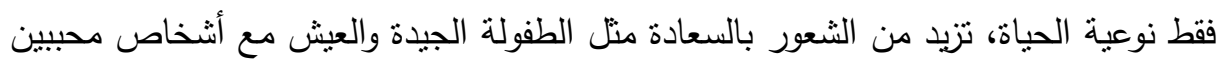

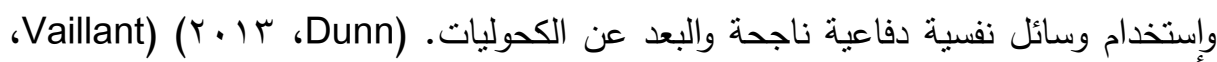

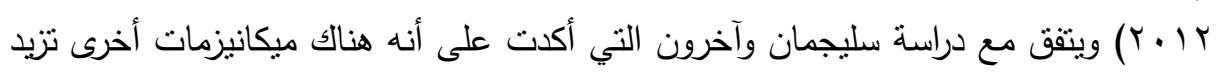

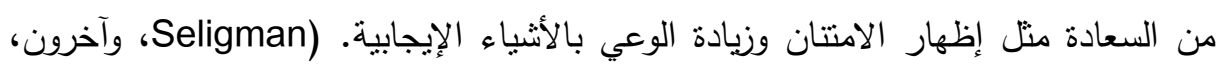

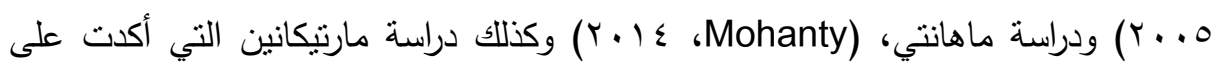

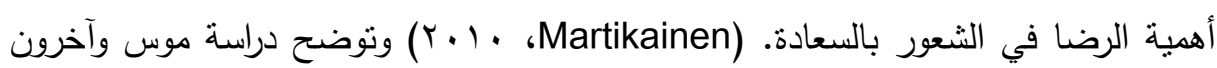

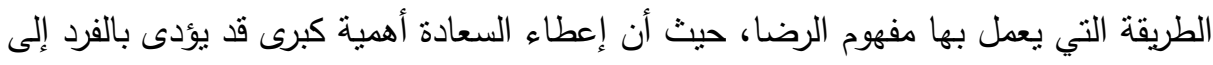

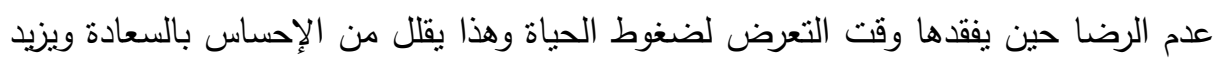

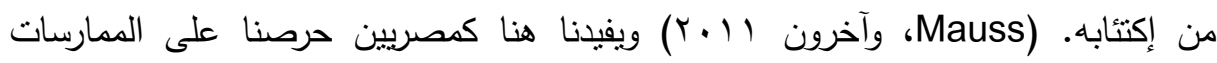

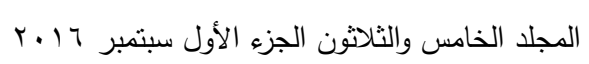


الدينية فهي تساهم في رفع سعادتتا بالرغم من مصاعب الحياة، وهذا ما أكدت عليه دراسة

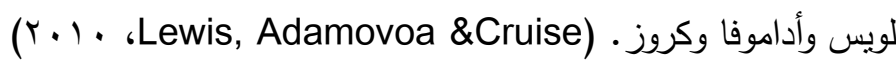

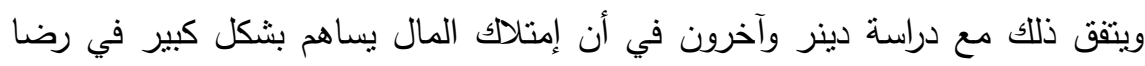
الفرد عن حياته، لكنه لايضمن الحصول على المشاعر الإيجابية، بل هي تأتي من منبهات

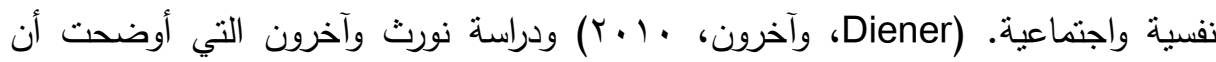
زيادة الدخل لها تأثثير محدود على زيادة السعادة، فبعد إسهامها في سد الإحتياجات الأساسية،

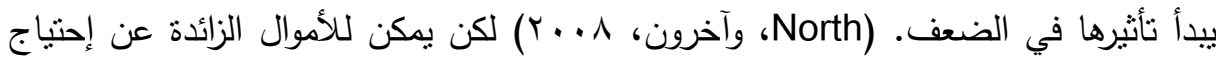

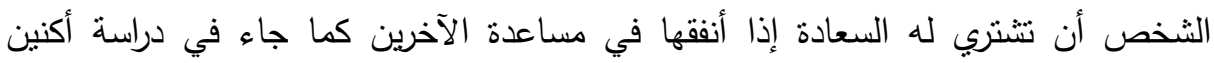

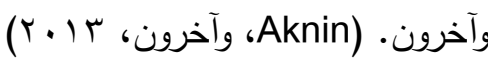
الفرض الثاني: يوجد فرق دال احصائياً بين متوسط درجات الإرادة والتحكم في الذات باختلاف نوعية الحياة. لم يظهر تأثثر لنوعية الحياة على قوة الإرادة والتحكم في الذات. العلاقة بين السعادة وقوة الإرادة: الفرض الثالث: هناك ارتباط دال احصائياً بين السعادة وقوة الإرادة. هناك علاقة إرتباط بين السعادة وقوة الإرادة بشكل عام، فكلما زادت السعادة، زادت قوة الهاده الإرادة والعكس صحيح. وهناك علاقة إرتباط بين كل من المؤشرات الفرعية لقوة الإرادة وهي

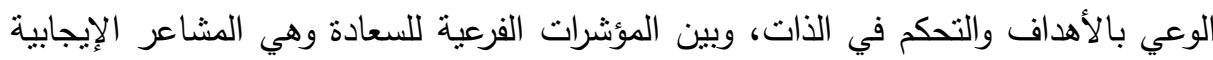
والرضا وتحقيق الأهداف والثنغف بالحياة وتحقيق الذات والعلاقات الاجتماعية والثقة بالنفس ولئ

كذللك ظهر أن قوة الإرادة ومقاييسها الفرعية تؤثر على السعادة.

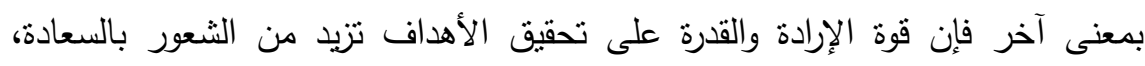

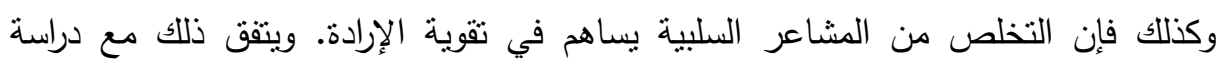

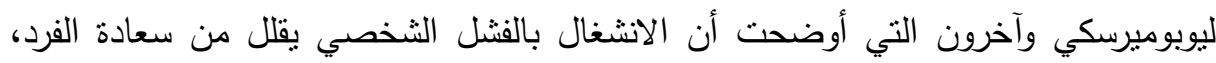


وهذا الانشغال يصاحب أيضا أصحاب الإرادة الضعيفة ويمنعهم من تحقيق أهدافهم.

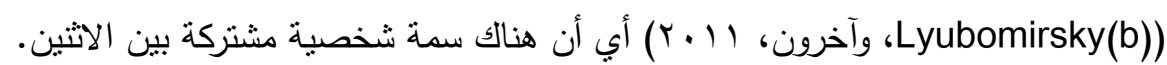

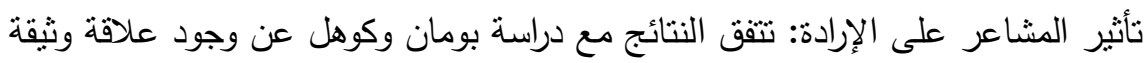

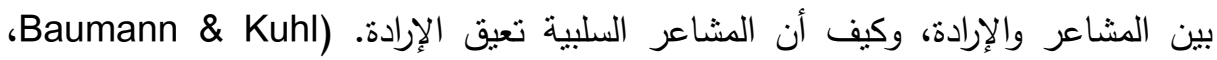

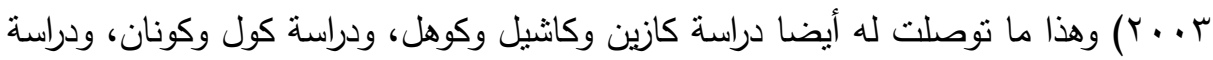

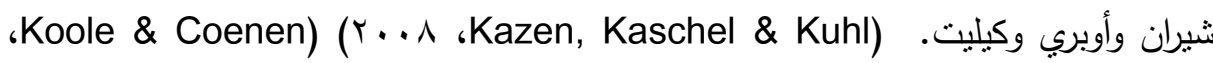
ودراسة جاراميللو التي أظهرت أن (Y..V S Sheeran, Aubrey \& Kellett) (Y..V

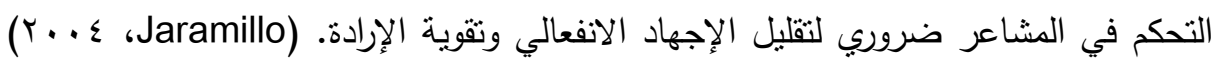

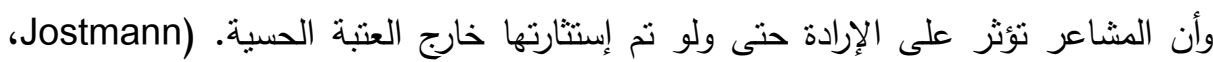

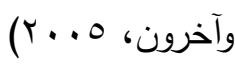

أما من ناحية تأثثر الإرادة على المشاعر ، فقد أظهرت دراسة كازين وبومان وكوهل أن تحقيق الأهداف الثخصية يزيد من السعادة، وهذا لا يحدث عند تحقيق أهداف الآخرين، (Ylazen, Baumann \& Kuhl)

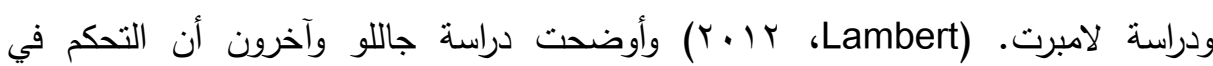

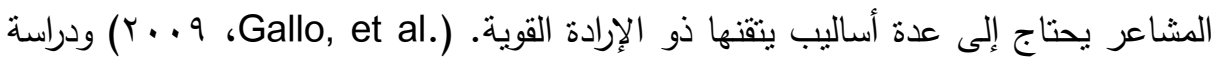

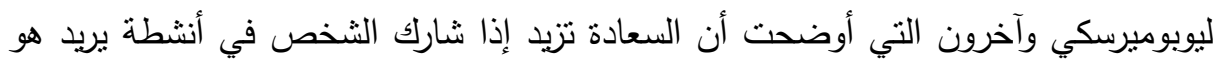

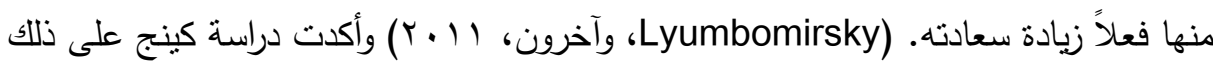

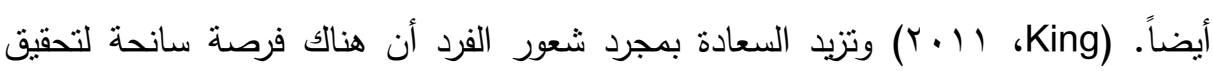

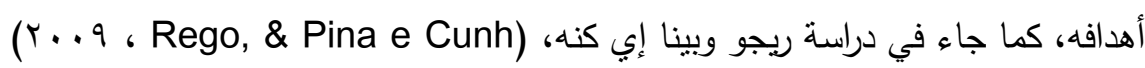
يتضح هنا أن قوة الإرادة وتحقيق الأهداف نؤثز على السعادة وذلك في مجتمعنا

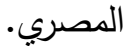




\section{العلاقة بين السعادة ونوعية الحياة:}

الفرض الرابع: هناك ارتباط دال احصائياً بين السعادة ونوعية الحياة. • هناك ارتباط بين السعادة ونوعية الحياة بشكل عام، وتؤثر جودة الحياة على السعادة بنسبة

قليلة.

هنالك ارتباط بين نوعية الحياة والمشاعر الإيجابية وتحقيق الذات. وتؤثر جودة الحياة على

المشاعر الإيجابية وتحقيق الذات بنسبة قليلة.

• لا يوجد ارتباط بين نوعية الحياة والرضا وتحقيق الأهداف والثغف بالحياة والعلاقات

الاجتماعية والثقة بالنفس والصحة الجسدية.

العلاقة بين الإرادة ونوعية الحياة:

الفرض الخامس: هناك ارتباط دال احصائياً بين قوة الإرادة ونوعية الحياة. • • ل ال يوجد علاقة بين الإرادة ونوعية الحياة.

• لم أجد في الدراسات السابقة بحث حول العلاقة بين قوة الإرادة ونوعية الحياة، لكن عدم العداة وجود إرتباط هنا هو أمر المنطقي، لأن هناك إرتباط بين السعادة وقوة الإرادة. وبما أنه لم لم لمأل

يظهر إرتباط بين السعادة وجودة الحياة، فلن يكون هناك إرتباط بين الإرادة وجودة الحياة. بالإضافة إلى أن الأفراد يميلون للكنب فيما يخص مستودى معيشتهم، فهم يميلون دائماً

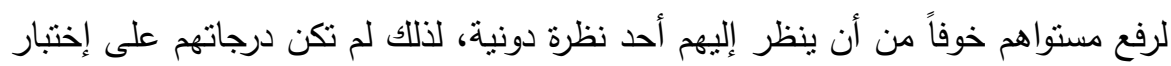
جودة الحياة بالدقة المطلوبة.

\section{التجوسيايت}

تعتمد قوة الإرادة على سمات شخصية واضحة ومعروفة الآن، لذلك يمكن لبرامج التربية

وبرامج التتمية البشرية أن تستفيد بها، بحيث يكون متاح للآباء ولكي من يريد أن يقوب إرادته لإنه

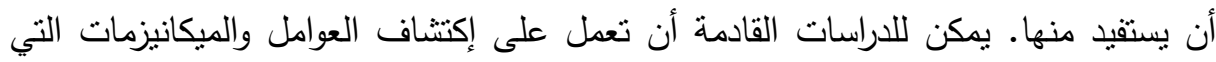
يستخدمها المصريون في مواجهة صعوبات الحياة والتوصل إلى تحقيق أهدافهر. 


\section{مرايج الصراهة}

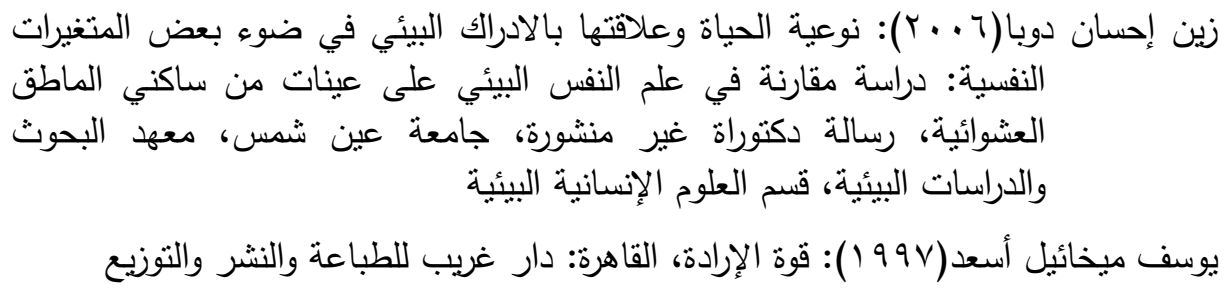

Aknin, Lara B., et al., Prosocial Spending and Well-Being: CrossCultural Evidence for a Psychological Universal, Journal of Personality and Social Psychology, Vol. 104, No. 4, pp. 635652, 2013.

Baumann, Nicola \&Kuhl, Julius, Self-Infiltration: Confusing Assigned Tasks and Self-Selected in Memory, Personality and Social Psychology Bulletin, Vol. 29, pp. 487-498, 2003.

Bongers, Karin C. A. \& Dijksterhuis, Ap, Consciousness as a Troubleshooting Device? The Role of Consciousness in Goal Pursuit. In Morsella, Ezequiel (Editor), Bargh, John A. (Editor) \& Gollwitzer, Peter M. (Editor), Oxford Handbook of Human Action,(603-624) New York: Oxford University Press, 2009.

Carver, Charles S. \& Scheier, Michael F., Action, Affect, and TwoMode Models of Functioning. In Morsella, Ezequiel (Editor), Bargh, John A. (Editor) \& Gollwitzer, Peter M. (Editor), Oxford Handbook of Human Action, (298-327) New York: Oxford University Press, 2009.

Diefendorff, James M., et al., Action-State Orientation: Construct Validity of a Revised Measure and Its Relationship to WorkRelated Variables, Journal of Applied Psychology, Vol. 85, No. 2, pp. 250-263, 2000.

Diener, Ed, et al., Wealth and Happiness Across the World: Material Prosperity Predicts Life Evaluation, Whereas Psychosocial

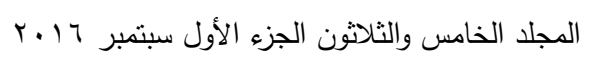


Prosperity Predicts Positive Feeling, Journal of Personality and Social Psychology, Vol. 99, No. 1, pp. 52-62, 2010.

Dunn, Dana S., Living Well: Taking the Long(itudinal) [Sic.] Veiw, Journal of Social and Clinical Psychology, Vol. 32, No. 7, pp. 809-812, 2013.

Gallo, Inge Schweiger, et al., Strategic Automation of Emotion Regulation, Journal of Personality and Social Psychology, Vol. 98, No. 1, pp. 11-31, 2009.

Ganser, William G., Pursuing Happiness with Gratitude and Kindness: an Experimental Intervention Comparing Cognitive and Behavioral Activities, Master Degree, North Arizona University, 2012.

Gollwitzer, Peter M., Parks-Stamm, Elizabeth J. \& Oettingen, Gabriele, Living on the Edge: Shifting Between Nonconscious and Conscious Goal pursuit. In Morsella, Ezequiel (Editor), Bargh, John A. (Editor) \& Gollwitzer, Peter M. (Editor), Oxford Handbook of Human Action, (603-624) New York: Oxford University Press, 2009.

Helliwell, John F. (Editor), Layard, Richard \& Sachs, Jeffrey, World Happiness Report 2013, New York: UN Sustainable Development Solutions Network, 2013.

Ianni, Phillip Anton, Does Frequent Use of Signature Strengths Enhance Academic Well-Being?, Master Degree, The University of Windsor, Department of Psychology, 2012.

Jaramillo, Jorge Fernando, The Impact of Action/State Orientation on Salespersons' Job Performance, PH. D., University of South Florida, College of Business Administration, 2004.

Jayawickreme, Eranda, Forgeard, Marie J. C., \& Seligman, Martin E. P., The Engine of Well-Being, Review of General Psychology, Vol. 16, No. 4, pp. 327-342, 2012. 
Jostmann, Nils B., , et al., Subliminal Affect Regulation: The Moderating Role of Action vs. State Orientation, European Psychologist, Vol. 10, No. 3, pp. 209-217, 2005.

Kazen, Miguel, Baumann, Nicola \& Kuhl, Julius, Self-Infiltration vs. Self-Compatibility Checking in Dealing with Unattractive Tasks: The Moderating Influence of State vs. Action Orientation, Motivation and Emotion, Vol. 27, No. 3, pp. 157-197, September 2003.

Kazen, Miguel, Kaschel, Reiner \& Kuhl, Julius, Individual differences in intention initiation under demanding conditions: Interactive effects of state vs. action orientation and enactment difficulty, Journal of Research in Personality, Vol. 42, No. 3, pp. 693-715, June 2008.

King, Kevin, The Spiral Staircase: Developing a Happiness Increasing Training Program for Workers, Ph. D., Chicago School of Professional Psychology, 2011.

Koole, Sander L. \& Coenen, Linda H., Implicit Self and Affect Regulation: Effects of Action Orientation and Subliminal Self Priming in an Affective Priming Task, Self and Identity, Vol. 6, pp. 118-136, 2007.

Lambert, Louise T., Running Towards Authentic Happiness: A Phenomenological Exploration, $\mathrm{Ph}$ D., Northcentral University, 2012.

Lyunbomirsky, Sonja, et al., Becoming Happier Takes Both a Will and a Proper Way: An Experimental Longitudinal Intervention to Boost Well-Being, Emotion, Vol. 11, No. 2, 391-402, 2011.

Lyubomirsky, Sonja, et al., The Cognitive and Hedonic Costs of Dwelling on Achievement-Related Negative Experiences: Implications for Enduring Happiness and Unhappiness, Emotions, Vol. 11, No. 5, pp. 1152-1167, 2011.

Martikainen, Liisa, Life Satisfaction of University-Educated Young Adults. In Makinen, Anna (Editor) \& Hajek, Paul (Editor),

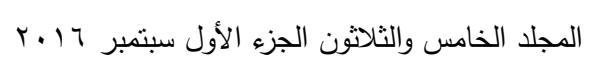


Psychology of Happiness, (pp. 127-141), New York: Nova Science Publishers, Inc, 2010.

Mauss, Iris B., et al., Can Seeking Happiness Make People Unhappy? Paradoxical Effects of Valuing Happiness, Emotions, Vol. 11, No. 4, pp. 807-815, 2011.

Miller, William R., \& Atencio, David J., Free Will as a Problem. In Baer, John (Editor), Kaufman, James C. (Editor), \& Baumeister, Roy F. (Editor), Are we Free? Psychology and Free Will, Oxford Scholarship Online, 2008.

Mohanty, Madhu S., What Determines Happiness? Income or Attitude: Evidence from the U.S. Longitudinal Data, Journal of Neuroscience, Psychology, and Economics, April, 2014.

Preston, Jesse \& Wegner, Daniel M., Elbow Grease: When Action Feels Like Work. In Morsella, Ezequiel (Editor), Bargh, John A. (Editor) \& Gollwitzer, Peter M. (Editor), Oxford Handbook of Human Action,(569-586) New York: Oxford University Press, 2009.

Rego, Armenio, \& Pina e Cunh, Miguel, Do the Opportunities for Learning and Personal Development Lead to Happiness? It Depends on Work-Family Conciliantion, Journal of Occupational Health Psychology, Vol. 14, No. 3, pp. 334348, 2009.

Richardson, Sara C., America and its Discontents: The Pursuit of Happiness in the 21st Century, Master of Arts, Pacifica Graduate Institute, 2013.

Seligman, M. E. P, Authentic Happiness, New York: Free Press, 2002.

Seligman, Martin E. P., et al., Positive Psychology Progress: Empirical Validation of Interventions, American Psychologist, Vol. 60, No. 5, pp. 410-421, 2005.

Sheeran, Paschal, Aubrey, Richard \& Kellett, Stephen, Increasing Attendance for Psychotherapy: Implementation Intentions 
أحمد مصطفى العتيق وآخرون

and the Self-Regulation of Attendance-Related Negative Affect, Journal of Consulting and Clinical Psychology, Vol. 75, No. 6, pp. 854-863, 2007.

Vaillant, George E., Triumphs of Experience: The Men of the Harvard Grant Study, Cumberland: Harvard University Press, 2012.

\title{
THE RELATIONSHIP BETWEEN VOLITION AND HAPPINESS ACCORDING TO QUALITY OF LIFE.
}

\author{
AlAteeq, A. M. ${ }^{(1)}$; Hany, A. F. ${ }^{(1)}$ and Yassin, H. A. \\ 1) Institute of Environmental Studies and Research, Ain Shams \\ University.
}

\begin{abstract}
This study was conducted to explore the relationship between happiness and volition in the Egyptian society, and their relation with quality of life. The descriptive method was used. The tools were a happiness scale, a volition scale, and a quality of life scale. The sample was 105 males and females. Statistics showed that happiness in general and specifically, positive feelings and self-accomplishment increase at groups of people who are living in high quality of life. Concerning satisfaction, goal accomplishment, passion to life, social relations, selfconfidence and physical health, there was no difference between different groups. Quality of life has no effect on volition. There is a relationship between happiness and volition in general. There is a relationship between happiness and quality of life in general. There is no relationship between volition and quality of life. It was recommended to use the results in the different programs in education and human development programs that aim at improving willpower. The future studies can work on discovering the factors and mechanisms that Egyptians use to face everyday difficulties and reach their goals.
\end{abstract}

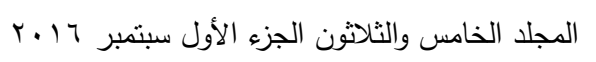

